\section{Application of a Multiple-Band Ligator in Active Variceal Bleeding}

Endoscopic ligation of esophageal varices is more effective, and carries a lower risk of adverse effects, than sclerotherapy $(1,2)$. Conventional ligating devices are introduced via an overtube, and carry only one rubber band. They therefore have to be withdrawn, reloaded, and reintroduced after the application of each ring. To overcome the need for repeated intubation and the need for an overtube, devices carrying multiple rings have been described recently, and have been used in elective variceal banding $(3,4)$. Conventional ligation has been successfully used in acute bleeding from esophageal varices (5). The use of a device with multiple rings and without an overtube in active variceal bleeding has not previously been described.

Following several successful applications of a multiple-band ligator (SpeedBand, Boston Scientific, USA) in elective variceal ligation, we were able to apply this new device in two patients with posthepatitic liver cirrhosis and active bleeding from esophageal varices. One patient presented with the first episode of bleeding from esophageal varices. Bleeding was visualized from a varix at about $2 \mathrm{~cm}$ above the esophagogastric junction. The endoscope was withdrawn, the multiple band ligator was connected, and the endoscope was introduced again. The first ring was applied after suction of the varix at $1-2 \mathrm{~cm}$ distal to the bleeding, while the second one was administered directly to the bleeding point. Bleeding was stopped by these two rings within five minutes of the diagnosis. Three further rings were applied to two other large varices. One of these rings detached from the varix without causing bleeding or trauma. One week after this emergency procedure, no more large varices were observed. The patient has done well for more than two months.

In the other patient, there was spurting bleeding originating from a very large varix at the esophagogastric junction (Figure 1 a), and there were two other large but nonbleeding varices present. Two rings were released onto the bleeding varix, but could not be securely fixed. Bleeding was therefore stopped only after administering a third ring to the large varix (Figure $\mathbf{1 b}$ ). Two further rings were applied to the other varices. One day later, the patient had an episode of slight rebleeding. The site of recurrent bleeding was on the same varix as the day before, but distal to the well-connected band, and it was controlled by injection selerotherapy.

In these two cases, active variceal bleeding was controlled by the application of a multiple-band ligator device. The ability to apply several rings immediately if bleeding is not controlled by the first ring ist the major advantage of this procedure. In addition the ease and the speed of the procedure clearly favor the use of multipleband ligation as compared to conventional devices, especially in acute hermorrhage. Detachment of rings from varices, however, is presumably likely to occur more often than with conventional devices.
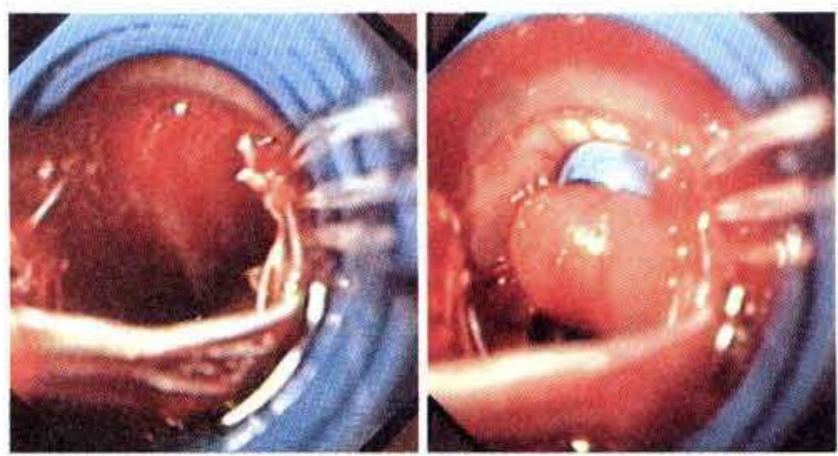

Figure 1a: Bleeding at the two o'clock position from a very large varix close to the esophagogastric junction. The blue rings of the multiple band ligator are still connected to the devices. $\mathbf{b}$ Control of bleeding after attachment of the third rubber band.

Multiple-band ligator devices can be used in cases of active bleeding from esophageal varices. Further experience is needed, however, to establish its role in hemostasis and the prevention of rebleeding.

\section{Sackmann, A. L. Gerbes}

Dept. of Medicine II, Klinikum Grosshadern, University of Munich, Munich, Germany

\section{References}

1. Laine L, Cook D. Endoscopic ligation compared with sclerotherapy for treatment of esophageal variceal bleeding: a metaanalysis. Ann Intern Med 1995: 123: 280-7.

2. Gerbes AL, Fischer G, Holl J, Paumbartner G. Therapie der Varizenblutung. Disch Med Wochenschr 1996; 121: 416-23.

3. Hashizume M. Sugimachi K, Kishihara F, Kawanaka H, Ohta M, Tomikawa M, et al. A serial transparent endoscopic elastic band ligator. Gastrointest Endose 1995; 42: 169-70.

4. Hochberger J, Reh H, Hahn EG. Neuer Multiligatur Applikator zur endoskopischen Therapie von Oesophagusvarizen. Dtsch Med Wochenschr 1995; 120: 1300-1.

5. Gimson AES, Ramage JK, Panos MZ, Hayllar K, Harrison PM, Williams R, et al. Randomised trial of variceal banding ligation versus injection sclerotherapy for bleeding ocsophageal varices. Lancet $1993 ; 342: 391-4$.

Corresponding Author

M. Sackmann, M. D.

Dept. of Medicine II

Klinikum Grosshadern

University of Munich

81366 Munich

Germany

Fax: $+49-89-7004418$ 